6. A necessary truth is not impossible

from 2 and 3 together. But what is not impossible might be true or might be false. Since according to 1 what is necessarily true could not possibly be false, Mr. Bar-Hillel is back with the original paradox. I do not see therefore that he has made any progress toward a solution.

Mr. Bar-Hillel thinks too that it is a blunder to say that "if what is possibly true could not be false then it would be necessarily true." Perhaps he would be able to see the point a little more readily were it stated as

7. If what is possibly true could never be false, it would be necessarily true.

But Mr. Bar-Hillel seems to have something else in mind, for on page 92 he interprets 4 to mean

$4^{\prime}$. What is contingently true could be false and on page 93 interprets it to mean

$4 "$. What is not impossible could be false.

He seems to be holding that $4^{\prime}$ is necessarily true, and $4^{\prime \prime}$ is false. But why he thinks this is not clear.

Received March 3, 1956

\title{
NOTES
}

${ }^{1}$ Philosophical Studies 6:31-32 (1955).

${ }^{2}$ Ibid., Pp. 92-93.

\section{On Misremembering Dreams}

\author{
by LEONARD LINSKY
}

UNIVERSITY OF MICHIGAN

A CRUCIAL question concerning the logic of the language we use in talking about some of our "inner" experiences concerns the sense in which we can be said to misreport or misremember them. An examination of this issue will help us to see why, in philosophy, we are sometimes tempted to speak of such experiences as "private" or "hidden" from others while knowable only to ourselves. In these philosophical moods we are inclined to say that only I know what I am saying to myself. Others may guess or have beliefs on this matter but only I know. Similarly, in the matter of dreams, I seem to be in a position of "privileged access." I know at first hand what I dream, while others must rely on more or less good but indirect evidence. 
It is my view that the chief source of our difficulties in this area lies in an uncritical use of such key words of the fact-stating use of language as "know," "believe," "fact," and "report." We mistakenly import the logic of these expressions, when employed in straightforward fact-stating uses, into the entirely different set of uses of language involved in reporting such things as our dreams and silent soliloquies.

I should like in this note then, to indicate some of the important differences between reporting such things as the number of chairs in a room and reporting "private" experiences such as dreams. One important distinction to be used here comes from Wittgenstein's Philosophical Investigations (Part II, xi). "The criteria for the truth of the confession that I thought such-and-such are not the criteria for a true description of a process. And the importance of the true confession does not reside in its being a correct and certain report of a process. It resides rather in the special consequences which can be drawn from a confession whose truth is guaranteed by the special criteria of truthfulness."

What is the contrast which Wittgenstein is here making between the concept of truth and the concept of truthfulness? The criteria for the truthfulness of a report are just the criteria which are used in deciding that the reporter is not telling a lie (but is speaking truthfully). One point of Wittgenstein's remark is the observation that the criteria for the truth of our reports on our thoughts are just the criteria for the truthfulness of these reports.

Consider the distinction between the truth of a report on, say, the number of chairs in the next room and the truthfulness of such a report. It is clear that the concepts are distinct in this case, since I can give a false report even though I fully intend to give a true one. But in the case of reporting our dreams (thoughts, imaginations, silent soliloquies) the whole notion of the correctness of the report, as distinct from its truthfulness, seems to lose its point. The reason for this is connected up with the fact that the sense in which others' reports on their dreams can be said to "agree" with the "facts" they report is quite different from the kind of agreement involved in the more obvious sorts of factual statements. For I must finally rely on the account which others give as to the content of their dreams (thoughts, images). I can question the truthfulness of these accounts, but not (independently of this) their truth. And this makes the very notion of a "report" seem idle here. Against someone's truthful account as to the content of his dreams, nothing logically can count as conclusive evidence that the account is false except another of his truthful accounts. Wittgenstein seems to be making this point when he says (Part II, xi), "Assuming that dreams can yield important information about the 
dreamer, what yielded the information would be truthful accounts of dreams. The question whether the dreamer's memory deceives him when he reports the dream after waking cannot arise, unless indeed we introduce a completely new criterion for the report's 'agreeing' with the dream, a criterion which gives us a concept of 'truth' as distinct from 'truthfulness' here."

But suppose now that we shift from a consideration of the correctness of other people's reports of their dreams to query our own accounts to others (or ourselves) of our own dreams. Am I in a position of privileged access? Can I make a comparison between my account and the thing itself which others are barred from making? It seems to me that this is not so. For all I can do is to accept the account which seems to be correct (supposing that I have given more than one account). As in the case of other people's dreams the criteria for the truth and the criteria for the truthfulness were identical so in the case of my own accounts of my own dreams the criteria of correctness and the criteria for seeming to be correct become the same. Of course, I cannot query my own truthfulness. I can no more "compare" my account of my dreams with the dream itself than I can "compare" someone else's account of his dream with his dream. I may try to compare my account of my dream with what I remember myself to have dreamt. But what would count as establishing that I have misremembered my dreams? We don't, in practice, divide people into the two classes of those who remember correctly the contents of their dreams and those with poor memories in this respect. How could one tell to which of these two classes he (or anyone else) belongs? Well, perhaps immediately upon waking I wrote the dream down in my diary and I find now (some time later) that my present recollection does not accord with this earlier written account. Which account shall I trust? Won't I simply take the account which now seems to me correct? For as regards the correctness of my memory for the contents of my dreams there is no test for distinguishing a correct memory from an incorrect one which only seems to be correct. And hence there really cannot be this sort of issue as to the correctness of my memory for my dreams.

Another way of getting to see the peculiar idleness of the question as to the correctness of a report (not its truthfulness) on a dream is to observe that nothing really can turn on this "issue." If someone gives me a false report as to the strength of a building badly shaken in an earthquake, this false report can result in the death of many human beings. But nothing turns on what we dream, though our accounts of them can be interesting and informative to psychoanalysts and perhaps to other people as well.

Received January 15, 1956 